\title{
The spatial distribution of soil lead pollution in the Middle Mukuvisi Catchment, Harare, Zimbabwe
}

\section{Boycen Kumira Mudzengi}

Department of Geography and Environmental Science. Great Zimbabwe University. P.O. Box 1235. Masvingo. Zimbabwe. Email: boycenmudzengi@gmail.com.
Abstract. This research determined the spatial variation in soil lead pollution in the Middle Mukuvisi Catchment in Harare. Lead is one of the commonest urban pollutants and it induces negative effects on biophysical resources and humans. Part of the study area has been target of landfill programmes dating back to the 1950s. It is also subjected to industrial discharges from the Graniteside and Masasa Industrial Areas. The study catchment was stratified into two strata namely: Strata A $\left(8 \times 10^{5} \mathrm{~m}^{2}\right)$ and Strata B $\left(10 \times 105 \mathrm{~m}^{2}\right)$ upstream and downstream with respect of the centre of the landfilled area respectively. These strata were digitized in Arc View Geographic Information System (GIS). Stratification enabled the testing of differences in soil lead pollution levels in the two study strata. Thirty soil samples were then collected from random points in the study area for laboratory chemical analysis. Fifteen points were randomly selected for each stratum. The results showed that soil lead concentration varies spatially in the study catchment. In comparison the strata upstream has lower average soil lead concentration than strata downstream with respect to the centre of the landfilled area. However, the difference in soil lead concentration between the two strata is not significant $(p>0.05)$. This can be explained by introduction of lead into the study catchment by other sources of pollution upstream such as Masasa Industrial Area. The other sources of lead into the study strata besides landfill leachate can be leakages from fuel stations and leaded fuel spillages from vehicles. It is anticipated further research in this area will contribute to the sustainable utilization of urban river catchments, especially where they are used for dumping wastes.
Keywords: Soil lead pollution; Landfill; Leachate; Vegetation stress; Lead poisoning.

\section{Introduction}

This research aims to determine the spatial variation in soil lead concentration in the Middle Mukuvisi Catchment in Harare. Soil pollution is the condition of soil impurity caused by contamination (Klein, 1962; Singer and
Munns, 1996) and it induces negative effects on biophysical resources (Dolk and Vrijheid, 2003; Nicholson et al., 2003; Samson et al., 1988) and humans (Karrari et al., 2012; Lei et al., 2011). Soil heavy metal pollution induces vegetation stress (Beavington, 1973; Horler et al., 1980; Singh et al., 1989; Smith et al, 
2004). Heavy metal pollution also has adverse effects on human health (Davies, 1978; Fleming and Parle, 1977; Warren et al., 1971).

Lead is one of the commonest urban pollutants (Davies et al., 2009). Lead lowers primary production as it causes oxidative stress in plants evident by reduction in photosynthetic pigments (Reddy et al., 2005). This is observed through morphological symptoms of senescence such as chlorosis and fragmentation of leaves (Reddy et al., 2005; Mishra et al., 2006). This alters the physiologic structure of plants and consequently suppress primary production (Lu et al., 2000). Lead in contaminated soils can be taken up and accumulated in crops and plants and then exert potential risk to humans and animals through food chain (Lei et al., 2011; Davies and Holmes, 1972). Signs and symptoms of lead poisoning include hearing loss, anemia, renal failure and weakened immune system. Further, in children low level lead exposure can significantly induce motor dysfunctions and cognitive impairement (Karrari et al., 2012). These adverse health effects of lead have resulted in the general public exerting pressure upon governments to limit its emissions thereby reduce the exposure of the population to the metal.

Part of the study catchment is characterized by sanitary landfills and waste dumps. Landfills are used to deposit mainly solid wastes. They constitute potential sources of pollution since they may contain organic micropollutants, heavy metals and salts (Chenje et al., 1998). Other potential sources of soil pollution in the Middle Mukuvisi Catchment include industrial effluent in the Masasa Industrial Area, storm water from the City Centre and industrial discharges from the Graniteside Industrial Area (Zaranyika 1997). Landfill seepage also has the effect of diluting nitrates introduced into the catchment mainly through effluent from a fertilizer manufacturing plant in Masasa (Zaranyika et al., 1993).

A study on the effect of leachate from landfills along the Mukuvisi River showed that the landfilling in the industrial region along the stream had a strong influence on the heavy metal content of the stream (Zaranyika et al., 1993). Dissolved solids and conductivity also increased progressively as the landfills were approached along the same stretch of the river, suggesting that seepage from the landfills is responsible for the rise in ionic levels (Mathuthu and Zaranyika, 1997). Past studies also indicated that the nitrates were diluted by the landfill leachate as the levels dropped close to the landfill sites (Zaranyika, 1997). Leachate from landfills is negatively impacting on biophysical resources because the landfills are not properly planned and maintained (Chenje, et al., 1998).

Pollution of aquatic ecosystems in Zimbabwe is regulated by the Environmental Management Act of 2002 and the Water Act of 1998. These Acts prohibit the discharge of toxic matter into aquatic environments. They also provide for the monitoring of pollution and its impact on water resources. This is in line with the Ramsar Convention of 1971 and the Rio-Dublin Principles on aquatic ecosystems.

This research aims to determine the spatial variation in soil lead concentration in the Middle Mukuvisi Catchment in Harare. The study will compare soil lead pollution upstream and downstream with respect to the centre of the landfilled area in the study catchment.

\section{Hypothesis}

There is no significant difference $(p>0.05)$ in soil lead concentration between strata upstream and downstream with respect to the centre of the landfilled area in the Middle Mukuvisi Catchment. 


\section{Materials and Methods}

\section{Study area}

The study area stretches from upstream of Chiremba and just below Cripps roads on the banks of Mukuvisi River in Harare. Mean annual rainfall for the area ranges from $700-1000 \mathrm{~mm}$ with a 20\%-35\% coefficient of variation (Chenje et al., 1998). The soils are derived from granite and tend to be deep, clayey and acidic. Part of the study area has been target of landfill programmes dating back to the 1950 s. It is also subjected to industrial discharges from the Graniteside and Masasa Industrial Areas (Zaranyika, 1997). Furthermore, there is stream bank cultivation mainly for maize production during the rainy season. Six fuel stations are also in proximity of the study area which poses risk to soil contamination.

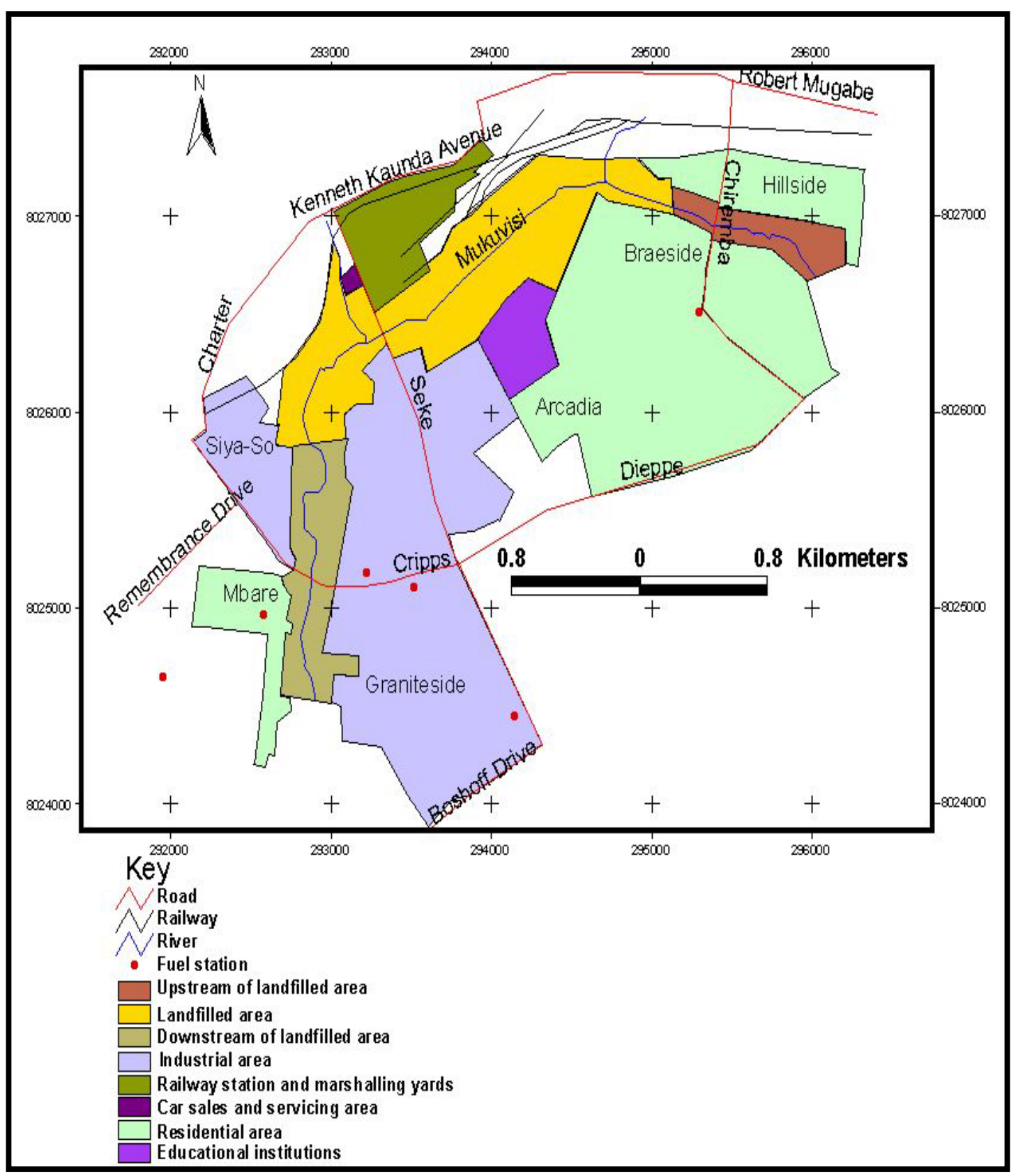

Figure 1. The location of study area. 


\section{Field sampling and soil lead pollution data collection}

The study catchment was stratified into two strata namely: Strata A $\left(8 \times 10^{5} \mathrm{~m}^{2}\right)$ and Strata B $\left(10 \times 10^{5} \mathrm{~m}^{2}\right)$ upstream and downstream with respect of the centre of the landfilled area respectively. These strata were digitized in Arc View Geographic Information System (GIS). Stratification enabled the testing of differences in soil lead pollution levels in the two study strata.

Thirty soil samples were collected from random points in the study area. The points were selected using the sampling capabilities of GIS. Fifteen points were randomly selected for each stratum (Figure 2). The soil samples were then taken into the Soil Science laboratory at the University of Zimbabwe for chemical analysis in order to determine their lead concentration. The lead concentration was determined using the Wet Digestion method. Lead was chosen because it is a typical constituent of sanitary landfill leachate (Peirce et al., 1998).

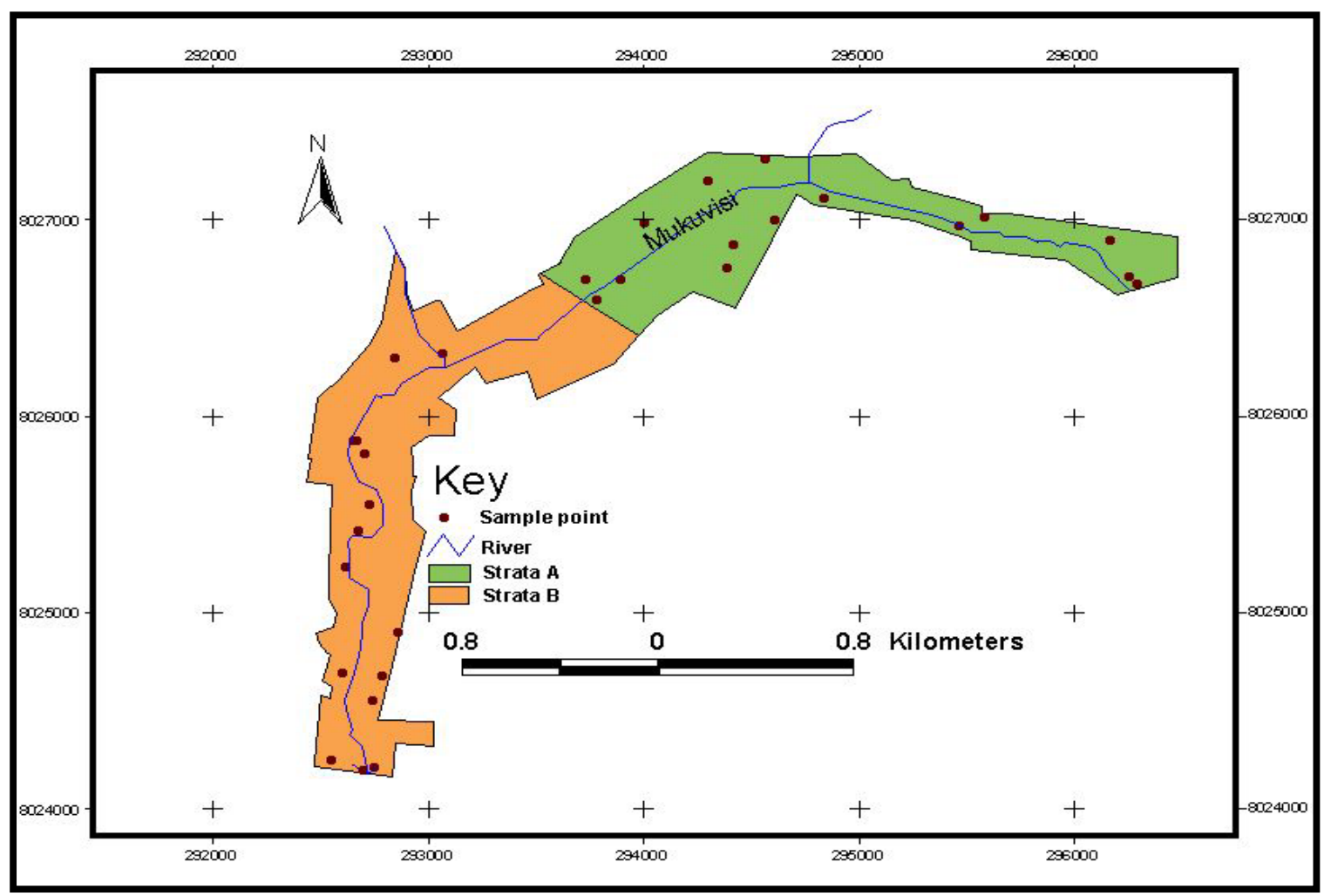

Figure 2. The location of sample points in study area.

\section{Exploratory data analysis}

All data were explored to determine the statistical tests to use. The soil lead concentration data set was tested for normality using the Kolmogorov-Smirnov Test. The data did not significantly assume a normal distribution.

\section{Inferential data analysis}

A non-parametric statistical significance test was applied to determine whether there are significant differences in soil lead concentration between Strata A (upstream with respect to the centre of the landfilled area) and Strata B (downstream with respect to the 
centre of the landfilled area). The statistical significance test was done in Statistica statistical software package.

\section{Spatial analysis}

Spatial analysis of soil lead concentration data was done using GIS. A map (model) showing soil lead concentration data was produced. Soil lead concentration data were also grouped with reference to criteria set by the Environmental Management Act.
Interpolation was used to produce the models showing soil lead concentration for the whole study catchment.

\section{Results}

Soil lead concentration varies spatially in the study catchment (Figure $3)$. In comparison the strata upstream has lower average soil lead concentration than strata downstream with respect to the centre of the landfilled area.

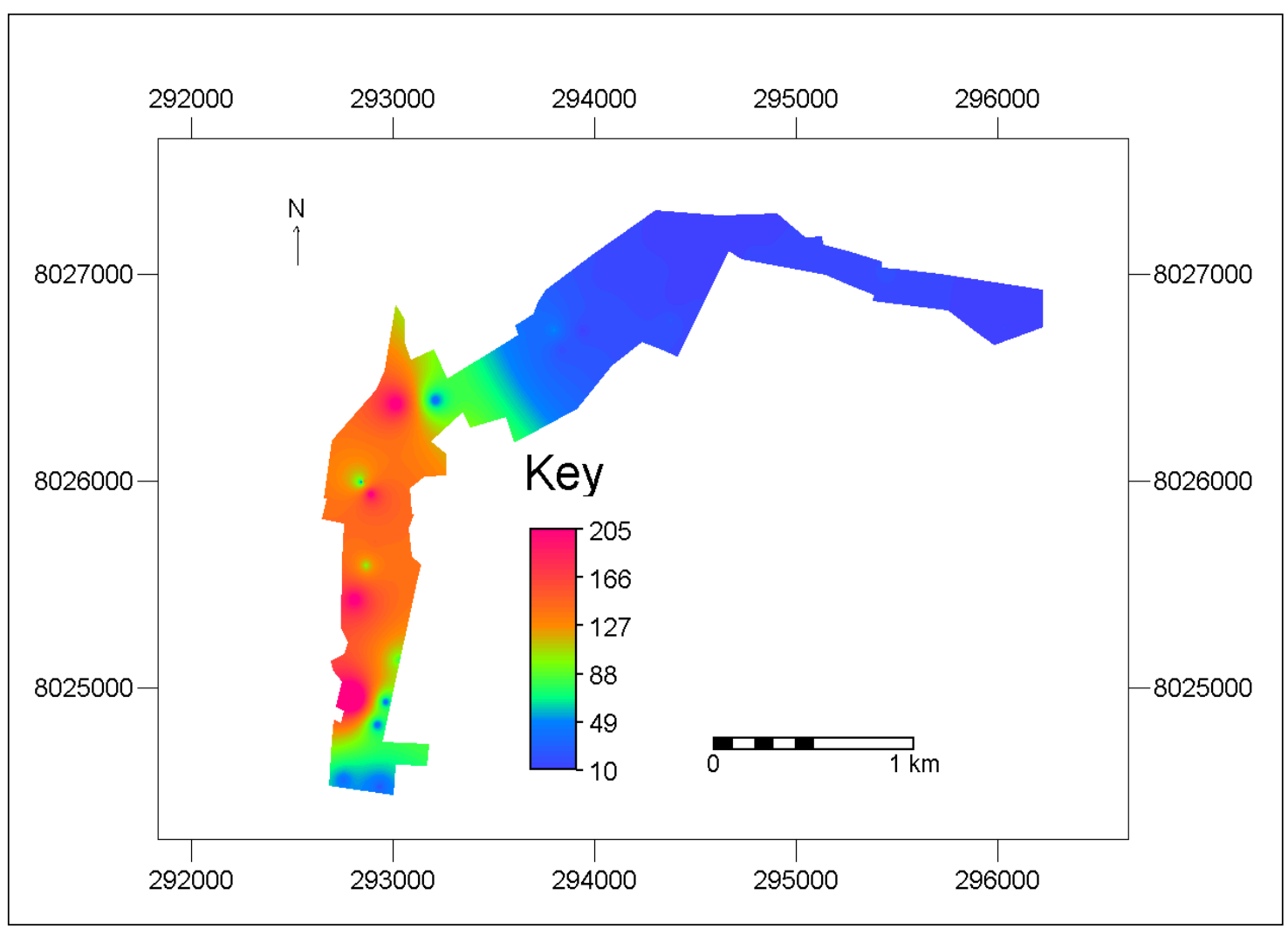

Figure 3. Soil lead concentration in the study area.

There is not much difference in average soil lead concentration in the two study strata with Strata A and Strata B having $23 \mathrm{mg} / \mathrm{L}$ and $22 \mathrm{mg} / \mathrm{L}$, respectively (Figure 4). The difference in the medians is also not significant $(p>0.05)$. This can be explained by introduction of lead into the study catchment by other sources of pollution upstream such as Masasa Industrial Area. This is also supported by (Zaranyika, 1997). The other sources of lead into the study strata besides landfill leachate can be leakages from fuel stations and leaded fuel spillages from vehicles. Furthermore, the landfill leachate may be containing small proportions of lead. 


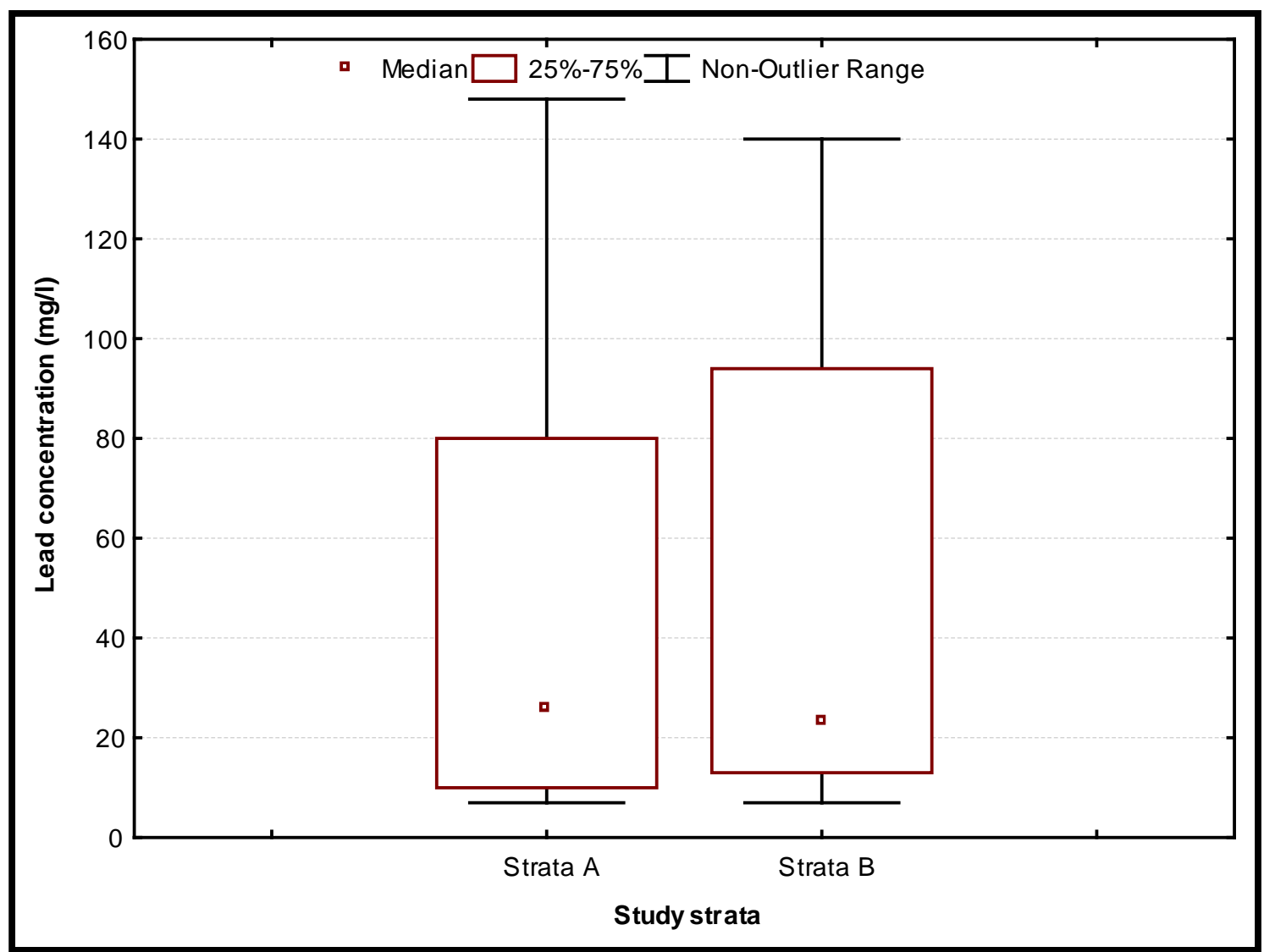

Figure 4. Soil lead concentration in the study strata.

Soil lead concentration data were also grouped with reference to criteria set by the Environmental Management Act to come up with a map showing areas with safe lead concentration, low, medium and high lead hazard (Figure 5). Most areas in Strata A upstream with respect to the centre of the landfilled area have a safe lead concentration with reference to criteria set by the
Environmental Management Act. On the other hand Strata B downstream with respect to the centre of the landfilled area has mostly high lead hazard and some sections with medium and low lead hazard. This shows that the landfills are a source of soil lead pollution downstream from the area where they are located in the Middle Mukuvisi Catchment. 


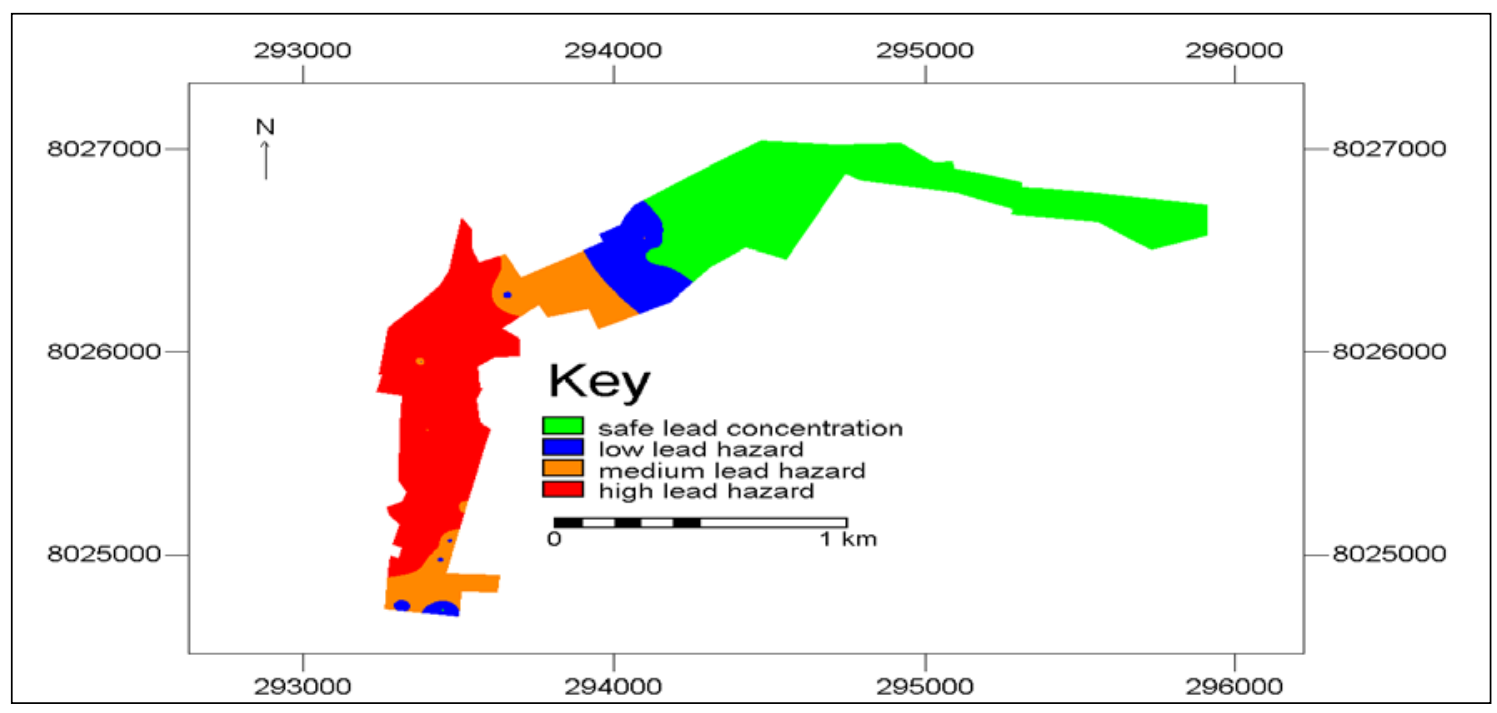

Figure 5. Soil lead concentration grouped data in the study catchment.

\section{Conclusion and implication for environmental management}

The study found out that landfill leachate is negatively affecting soil quality in the study catchment. The strata downstream with respect to the centre of the landfilled area has higher soil lead concentration than the strata upstream. However the difference in soil lead concentration in the two strata is not significant $(p>0.05)$. This may be due to the fact that landfill leachate is not the only source of lead in the study catchment.

The study recommends that funds raised through the polluter pays principle by the Zimbabwean environmental policy makers and planners be used in promoting further research on soil pollution. Further studies may also include the impact of soil pollution on aquatic vegetation resources and humans. It is anticipated further research in this area will contribute to the sustainable utilization and development of wetlands, especially where they are used for dumping wastes. The use of satellite imagery with high spatial resolution will also assist in this regard. For example, satellite sensors with finer resolution such as Quick Bird can detect plants that tolerate relatively high concentrations of soil pollutants. Such plants can then be used for decontaminating soils through bioremediation while ensuring they do not create a risk to their consumers.

Despite limitations of this study such as not considering all factors affecting soil lead pollution in the study catchment, we however believe that the study findings can still provide invaluable baseline information against which future changes can be measured and assessed.

\section{Conflict of interest statement}

Author declares that they have no conflict of interests.

\section{References}

Beavington, F. Contamination of soil with zinc, copper, lead and cadmium in the Wollongong City area. Australian Journal of Soil Research, v. 11, p. 7-31, 1973. https://doi.org/10.1071/SR9730027

Chenje, M.; Sola, L.; Paleczny, D. (Eds.). The State of Zimbabwe's Environment 1998. Harare: Government of the Republic of Zimbabwe, Ministry of Mines, Environment and Tourism, 1998. 
Davies, B. E. Plant-available lead and other metals in British garden soils. Science of the Total Environment, v. 9, p. 243- 262, 1978.

Davies, B. E.; Conway, D.; Holt, S. Lead pollution of London soils: a potential restriction on their use for growing vegetables. The Journal of Agricultural Science, v. 93, no. 3, p. 749-752, 2009. https://doi.org/10.1017/S00218596000391 62

Davies, B. E.; Holmes, P. L. Lead contamination of roadside soil and grass in Birmingham, England, in relation to naturally occurring levels. The Journal of Agricultural Science, v. 79, p. 479-484, 1972. https://doi.org/10.1017/S00218596 00025843

Dolk, H.; Vrijheid, M. The impact of environmental pollution on cogenital anomalies. British Medical Bulletin, v. 68, p. $25-45,2003$. https://doi.org/10.1093/ bmb/ldg024

Fleming, G. A.; Parle, P. J. Heavy metals in soils, herbage and vegetables from an industrialised area west of Dublin city. Irish Journal of Agricultural Research, v. 16, no. 1, p. 35-48, 1977.

Horler, D. N. H.; Barber, J.; Barringer, A. R. New concepts for the detection of geochemical stress in plants. Proceeding of the Eighth Annual Conference of the Remote Sensing Society. Reading: The College of St. Mark and St. John Foundation, Reading, 1980.

Karrari, P.; Mehrpour, O.; Abdollahi, M. A systematic review on status of lead pollution and toxicity in Iran; Guidance for preventive measures. DARU Journal of Pharmaceutical Sciences, 20:2, 2012. https://doi.org/ 10.1186/1560-8115-20-2

Klein, L. River pollution: Causes and effects. London: Butterworths, 1962.

Lei, M.; Tei, B.; Williams, P. N.; Zheng, Y.; Yuang, Y. Arsenic, cadmium, and lead pollution and uptake by rice (Oryza sativa L.) grown in greenhouse. Journal of Soils and Sediments, v. 11, no. 1, p. 115-123, 2011. https://doi.org/10.1007/s11368-010-0280-9

Lu, C. M.; Chau, C.W.; Zhang, J.H. Acute toxicity of excess mercury on the photosynthetic performance of cyanobacterium, S. platensis: Assessment by chlorophyll fluorescence analysis. Chemosphere, v. 41, n. $1 / 2$, p. 191-196, 2000. https://doi.org/10.1016/S0045-6535 (99)00411-7
Mathuthu, A. S.; Zaranyika, M. F. Water quality assessment by monitoring physical and chemical parameters and heavy metal pollution in Mukuvisi river in Zimbabwe. Harare: University of Zimbabwe Publications, 1997.

Mishra, D. R.; Narumalani, S.; Rundquist, D.; Lawson, M. Characterizing the vertical diffuse attenuation coefficient for down swelling irradiance in coastal waters: Implications for water penetration by high resolution satellite data. ISPRS Journal of Photogrammetry and Remote Sensing, v. 60 , no. 1, p. 48-64, 2006. https://doi.org/10.1016/j.isprsjprs. 2005.09.003

Nicholson, F. A.; Smith, S. R.; Alloway, B. J.; Carlton-Smith, L.; Chambers, B. J. An inventory of heavy metals inputs to agricultural soils in England and Wales. The Science of the Total Environment, v. 311, p. 205-219, 2003. https://doi.org/10.1016/ S0048-9697(03)00139-6

Peirce, J. J.; Weiner, R. F.; Vesilind, P. A. Environmental pollution and control. Boston: Butterworth-Heinemann, 1998.

Reddy, A. M.; Kumar, S. G.; Jyonthsnakumari, G.; Thimmanaik, S.; Sudhakar, C. Lead induced changes in antioxidant metabolism of horsegram (Macrotyloma uniflorum Lam. Verdc.) and bangalgram (Cicer arietinum L.). Chemosphere, v. 60, no. 1, p. 97-104, 2005. https://doi.org/10.1016/j.chemosphere.200 4.11.092

Samson, G.; Morisette, J.C.; Popovic, R. Copper quenching of the variable fluorescence in Dunaliella tertiolecta. New evidence for a copper inhibition effect on PSII photoinhibitory. Photochemistry and Photobiology, v. 48, no. 3, p. 329-332, 1988. https://doi.org/10.1111/j.17511097.1988.tb02829.x

Singer, M. J.; Munns, D. N. Soils: An introduction. New Jersey: Prentice Hall, 1966. Singh, D. P.; Khare, P.; Bisen, P.S. Effect of $\mathrm{Ni}^{2+}, \mathrm{Hg}^{2+}$ and $\mathrm{Cu}^{2+}$ on growth, oxygen evolution and photosynthetic electron transport in Cylindrospermum IU 942. Journal of Plant Physiology, v. 134, p. 406412, 1989. https://doi.org/10.1016/S01761617(89)80003-3

Smith, K. L.; Steven, M. D.; Colls, J. J. Use of hyperspectral derivative ratios in the rededge region to identify plant stress responses to gas leaks. Remote Sensing of 
Environment, v. 92, no. 2, p. 207-217, 2004. https://doi.org/10.1016/j.rse.2004.06.002

Warren, H. V.; Dela Vault, R. E.; Fletcher, K. W. Metal pollution: A growing problem in industrial and urban areas. Canadian Mining \& Metallurgical Bulletin, v. 7, p. 1-12, 1971.

Zaranyika, M. F.; Mtetwa, L.; Zvomuya, S.; Gongora, G.; Mathuthu, A.S. The effect of industrial effluent and leachate on the levels of selected trace heavy metals in the waters of Upper and Middle Mukuvisi River in Harare, Zimbabwe. Bulletin of Chememical Society of Ethiopia, v. 7, n. 1, p. 1-10, 1993. Available from: <https://www.ajol.info/ index.php/bcse/article/view/78407/68767> . Accessed on: Jan. 21, 2018.

Zaranyika, M.F. Sources and levels of pollution along Mukuvisi River: A review. Harare: University of Zimbabwe Publications, 1997. 